\title{
Pedagogies for the Engagement of Girls in the Learning of Proportional Reasoning through Technology Practice
}

\author{
Stephen Norton \\ Griffith University
}

\begin{abstract}
This paper reports the results of two interventions involving the integrated study of mathematics and technology practice to girls in Years 6 and 7. The focus of the study was to look at factors that contributed to girls' disengagement with mathematics study and seek pedagogical solutions for this. The key mathematics concepts embedded in the two interventions were proportional reasoning and ratio. A design based research methodology was adopted. The study started with the assumption that by integrating mathematics study with technology practice students would see the mathematics as authentic and understandable. The results of the first intervention indicated that a significant proportion of the girls did not develop the hoped for improvement in perceptions about the value of studying mathematics through technology practice, despite an improvement in their understanding of proportion and ratio. These results informed the second intervention in which modified tasks and pedagogy were implemented. The results of the second intervention were similar in terms of cognitive outcomes. However, when students were given explicit scaffolding in "within" and "beyond" the domain of mathematics integration as well as tasks that they considered authentic, student perceptions of mathematics study improved.
\end{abstract}

The understanding of the mathematical principles underpinning SET is necessary for participation within a technologically dependent society (Australian Academy of Technological Science and Engineering, 2002). Unfortunately, the importance of mathematical understanding is not being reflected either in female or male participation rates of SET subjects. Since 1980, the proportion of Year 12 students taking chemistry, physics, or advanced mathematics has nearly halved (Batterham, 2000). Barrington (2006) reported that between 1995 and 2004 there was a change in the percentage of Year 12 students taking advanced mathematics from $14.1 \%$ to $11.7 \%$; for intermediate mathematics the fall was $27.2 \%$ to $22.6 \%$ and there was an increase in students taking elementary mathematics from $37 \%$ to $46 \%$. This down downwards tend in the proportion of students taking higher mathematics is linked to Australia experiencing a critical shortage of scientists and engineers - this is restraining many vital industries and critical infrastructure projects in Australia (Batterham, 2000). Data produced by the Program for International Student Assessment (PISA) from over 12,500 Australian students) indicate that students' mathematics performance and intentions to engage in higher education of any form was one of the strongest of all student correlations factors (e.g., reported upon by Lokan, Greenwood \& Cresswell, 2001). It should be noted that this correlation does not imply causality; however, success or otherwise is linked to intentions to 
undertake further mathematics study and much of literature indicates that students who achieve success are more likely to develop self concepts that are compatible with further mathematics study (e.g., Eccles \& Wigfield, 1995; Ethington, 1992; Ma \& Willms, 1999). Arguably, success in mathematics for any student may be dependent on her or his ability to reason proportionally, a key and, at times, a difficult and challenging endeavour which underpins much of senior mathematics as well as critical understandings in the science disciplines of chemistry and physics. In the next section, a brief summary of research into proportional reasoning is presented to background the focus of this paper, which is on girls' engagement with, and learning of, proportional reasoning.

\section{Research on Proportional Reasoning}

Proportional reasoning is a concept that is central to mathematics and critical in understanding much science and technology (Nabors, 2002). In this paper the term "proportional reasoning" is used to describe the concepts and thinking required to understand rate, ratio and proportionality, including scale.

According to the National Council of Teachers of Mathematics (NCTM) Curriculum and Evaluation Standards (1989) document, "the ability to reason proportionally is of such great importance that it merits whatever time and effort that must be expended to assure its careful development" (p. 82). A number of authors (e.g., Ilany, Keret \& Ben-Chaim, 2004; Lo \& Watanabe, 1997) have noted that the essence of proportional thinking is multiplicative. Ability in such thinking is needed for an understanding of, for example, percentages, gradient, trigonometry and algebra. Lamon (1995) noted that proportional reasoning has typically been taught in "a single chapter of the mathematical text book, in which symbols are introduced before sufficient ground work has been laid for students to understand them" (p. 167). It is hardly surprising then, that many adolescent students who can apply numerical approaches meaningfully in an addition context, cannot apply such approaches to the multiplicative structures associated with proportional reasoning (e.g., Karplus, Pulos, \& Stage, 1983). Indeed, many of the error patterns that students demonstrate in relation to proportional reasoning problems, illustrate that students apply additive or subtractive thinking processes rather than multiplicative processes (Karplus et al. 1983). These authors also noted that exposing students to routine multiplication and division problems alone has not been effective in helping students to develop deeper understanding of proportional reasoning. Resnick and Singe (1993) put forward the hypothesis that early abilities to reason non-numerically about the relations among amounts of physical material, provide the student with a set of relational schema that eventually apply to numerically quantified material, and later to numbers as mathematical objects. Thus, it was recommended students be given time to explore and discuss authentic ratio and proportional situations/problems, and that they not be placed in the situation where algorithmisation and automatisation clogs the process of insight development (e.g., Ben-Chaim, Fey, Fitzgerald, Benedetto, \& Miller 1998). 
As a pre-requisite to proportional reasoning students need to understand fractions and decimals as well as multiplicative concepts (Lo \& Watanabe, 1997), however, the teaching and learning of fractions and decimals is problematic (e.g., Pearn \& Stephens, 2004). These authors have noted that many misconceptions that students hold are the result of inappropriate use of whole number thinking, including not understanding the relationship between the numerator and the denominator. Pearn and Stephens (2004) found that a major problem for students arose because they did not understand the part/whole relationships described in fraction notation, and recommended the use of multiple representations of fractions using discrete and continuous quantities and the number line.

Fractions and ratio are linked in many mathematics texts books. In particular Karplus, et al. 1983, p. 79) found that "students are shown how to represent the information in proportion word-problems as an equivalent fraction equation and to solve it by cross multiplying and then dividing." The problem with this approach is that in the context of fractions the numerator represents a part and the denominator the whole, while in the case of ratio both the numerator and the denominator represent parts. Thus, while the use of fraction notation in solving some proportion problems may seem expedient in setting out a multiplication and then division algorithm, it is likely to confuse students as to what really is the whole. In fractions this is the denominator, while in ratio it is the sum of the two parts. Since mathematics textbooks generally do not teach fractions and proportional reasoning in an integrated way, and usually this distinction is not made explicit, student confusion is understandable. Strategies for alleviating student confusion are sponsored by the National Science Foundation (2005) and Ben-Chaim, Fey, Fitzgerald, Benedetto, and Miller (1998). In a study of proportional reasoning among Grade 7 students, the performance of students taught using reasoning and rich connections associated with the Connected Mathematics Project (CMP) (National Science Foundation, 2005), were compared with the performance of those taught traditionally. It was found that the CMP activities helped students develop greater understanding and capability for solving relevant problems. Similarly, Ben-Chaim et al. (1998) found where students were given time and opportunities to explore and discuss authentic proportion situations they developed greater mathematical understanding.

\section{Disengagement of Girls in Hard Mathematics and Science Study}

Although the number of girls who now take senior mathematics has increased over recent decades, they remain underrepresented in double mathematics course (about 30\%) and in science, except Biology and Psychology (e.g., Cox, Leder, \& Forgasz, 2004; Custer, 2003). Similarly, there has been a fall in girls' enrolment in IT courses from $24 \%$ in 1991 to $19 \%$ in 1998 despite about an overall $30 \%$ increase in enrolments (Trauth, Nielsen, \& von Hellens, 2003). Cox et al. (2004) have noted that although girls tended to participate less in Victorian 
Curriculum Certificate of Education (VCE) science and mathematics subjects, gender comparisons are not simplistic with girls out performing boys on many indicators. None the less, the recent Australian data from PISA testing reported that boys out performed girls on 12 of the 18 individual mathematics questions reported upon (Lokan, Greenwood, \& Cresswell, 2001), although these differences were not statistically significant. These data support earlier studies that indicate non-significant gender differences in mathematical performance (e.g., Lokan, Ford \& Greenwood, 1996; 1997) and is supported by the meta analysis of research on gender difference between attitude and mathematical achievement conducted by Ma and Kishor (1997). Girls out performed boys on science literacy questions, again without statistical significance, In contrast, on reading literacy proficiency there were statistically significant differences favouring girls (Lokan, et al., 2001, pp 126). Clearly the issue of gender and mathematics and science performance is complex and at times contradictory and simplistic conclusions about gender differences in participation and performance are not warranted (Cox, Leder, \& Forgasz, 2004).

De Bono (2004, p. 15) has defined perception as "how we look at the world. What things we take into account. How we structure the world." Perceptions include likes and dislikes, anxiety, beliefs about self-efficacy and self-concepts. De Bono (2004, p. 5) has noted that "Outside of highly technical matters, perception is the most important part of thinking." Unfortunately, for many girls there is a perception that the teaching of mathematics has been decontexualised (see De Corte, 2004). Some of the critical issues that have led students to see mathematics this way include an over reliance on textbook work with a procedural focus, teacher dominated discourse, and closed learning activities that result in a lack of capacity to transfer knowledge (Hollingsworth, Lokan, \& McRae, 2003 - check this reference). Repeatedly students report that they neither understand important mathematical concepts nor appreciate why concepts are worth the effort of learning. Alternatively, they see mathematics as a way to entering further study, rather than acknowledging mathematics has intrinsic value in itself (Watt, 2005). Student perceptions that mathematics is a hard subject are linked to the image they have that mathematics is an abstract collection of rules (Townend, 2001), in particular, rules associated with number manipulations (Thompson, 1992). Students rarely associate mathematics with creativity or innovative thinking.

Many variables have been used to account for students, in particular girls' disengagement with mathematics study. The PISA data (Lokan et al., 2001., pp. 188-190) have indicated correlations between self-efficacy $(r=0.52)$, mathematics anxiety, mathematics self-concept $(r=0.41)$ and mathematical literacy. Selfefficacy refers to a student's beliefs about her or his capability to learn mathematics successfully and self-concept relates to student beliefs that her/his own ability is important to learning. Higher interest and enjoyment were also correlated with higher mathematical literacy, although interest and enjoyment were not necessary, in that a significant number of students had limited interest in mathematics but were motivated to succeed for extrinsic reasons. Overall 
higher student identity with respect to mathematics learning was found among boys.

Lokan et al (2001, p. 201) found that about $40 \%$ of the variation in mathematical performance can be explained by student attitudes and beliefs. They also found that about $80 \%$ of variance in Australian schools could be explained by within school factors rather than across school factors. It was concluded that mathematics performance was enhanced in an environment that was quiet and orderly and where students were eager to learn (Lokan et al., 2001). Clearly there are substantial data, which indicate that that how students perceive themselves as learners of mathematics was important to mathematical performance. The links between mathematics performance and enrolment with self-concept have been well explored and the interactions are complex, but most researchers acknowledge the importance of self-concept in student performance and enrolment intentions (e.g., Eccles \& Wigfield, 1995; Ethington, 1992; Cox, Leder \& Forgasz, 2004).

For many girls, disengagement with mathematics begins early in primary school, but becomes more pronounced as they progress towards the middle school (Fennema, 1996). The reasons for this decline in attitudes towards mathematics are complex. Boaler (1997) noted that the traditional method of teaching mathematics has the effect of alienating girls who became disenchanted with pedagogic variables related to pace, closed approaches and competitive environments. The research on those forms of pedagogy that are most likely address gender inclusive issues in mathematics learning have been linked to cognitive style research. For example, Head (1996) compared girls and boys preferred learning styles on a number of dimensions and noted that male students tended to extract, while females preferred to embed. Extraction is a mode of thinking that helps one to see a component in isolation, a style that is good, for example, for locating the component of a car that is malfunctioning. Embedding is akin to a more holistic way of thinking, better attuned for considering how the change in one component of a system affects another. Secondly, Head (1996) noted boys tended to be more impulsive, had a willingness to take risks, and were happier to launch into practical work even though they did not know what they were doing. In contrast, girls were more reflective and felt inhibited about commencing the task. They found, however, that such deliberation is likely to pay off in skills where care is needed such as essay writing. Thirdly, boys attributed their success to their own intellectual capacities and failure to outside factors. Girls attribute success to hard work and failure to their lack of ability. This makes girls susceptible to "learned helplessness." It was noted that the bland praise that girls typically receive in mathematics classes may have come from good intentions, but the pedagogic outcomes were unfortunate. Finally, boys tended to work well in competitive environments, while co-operative environments tended to suit girls better.

In summary, girls' perceptions of themselves including self-efficacy as well as about mathematics and mathematics learning is thought to be strongly related to within school factors. Factors that have been reported to be linked to girl's 
alienation from mathematics study include the traditional way mathematics has been taught (text book orientated, fast pace, closed approaches, competition), and preferred learning style (embedding vs extraction). The extent to which these issues have been considered in curriculum reforms is considered below.

\section{Curriculum Reforms to Mathematics Learning}

Previous research indicates that there is some urgency in designing new models of teaching mathematics and that different pedagogic models are needed to cater for diverse student groups. There has already been extensive research in the fields of gender inclusive mathematics curriculum (e.g., Walkerdine, 1988) and feminist pedagogies (e.g., Brady \& Dentith, 2001). However, the application of key attributes (students' experiences as central, safe places, development of student voice, understanding of power and agency, recognition of difference), as they apply to mathematics education have been less well documented.

The research is set against a background of broad curriculum reform since there has been a shift in the focus of mathematics towards a greater emphasis on powerful ideas associated with mathematical processes (Jones, Langrall, Thorton, \& Nisbet, 2002). NCTM Standards (2004) has encapsulated this trend world wide by giving pre-eminence to five process standards: problem solving, reasoning and proof, connections, communication, and representation. This is similarly reflected in Australian State syllabi (e.g., Queensland Studies Authority, 2004) which contain a rationale for thinking, reasoning and working mathematically, that is to see mathematics in situations encountered, to plan, investigate, conjecture, justify, think critically, generalise and to use technologies in the solving of problems. This shift in curriculum approach towards communication of reasoning and integration, or contextual problem based learning and reasoning has also found expression in attempts to integrate mathematics with science and technology. For example, the Connected Mathematics Project (National Science Foundation, 2005), New Basics curriculum documents (Education Queensland, 2001) and the Victorian Essential Learning Curriculum initiative (Victorian Curriculum \& Assessment Authority, 2005) have a strong emphasis on learning via integration across curricular through authentic tasks. A focus on rich tasks where mathematics and technology overlaps with other literacies is thought to enable students to develop modelling capacities that lead to greater mathematising and the conceptual use of mathematics (e.g., Ben-Chaim, Fey, Fitzgerald, Benedetto \& Miller, 1998: Nason, \& Woodruff, 2003). However, many teachers have found it difficult to integrate mathematics, in particular, into authentic and open-ended tasks and many tasks are such that it is difficult for teachers to generate abstraction, crucial to the development of mathematics and science concepts, principles and processes (Cooper, Nuyen, \& Baturo, 2003; Norton, McRobbie, \& Ginns, 2004). In addition, difficulties in planning, management and organisation have frustrated many teachers' attempts to implement an integrated approach to learning (Murdock \& Hornsby, 2003). 


\section{Mathematics Learning within a Technology Practice Learning Environment}

In this study the researcher was interested in examining factors that affected female student learning associated with proportional reasoning. It is also concerned with documenting students' perceptions of mathematics while they studied mathematics within an integrated design and technology teaching intervention. Design and technology offered the potential to learn mathematics in authentic and contextual settings consistent with the recent curriculum initiatives and recommendations outlined above. A new Technology syllabus (Queensland Studies Authority [QSA], 2003) has become mandatory in Years 1 to 10 in Queensland, thus it seemed that the integration of mathematics and technology learning was a worthwhile line of inquiry. A key aspect of the Technology Syllabus is "technology practice." Technology practice embodies the actions of investigation (identifying the problem and gathering information and data), ideation (planning and designing), production (creating and making), and evaluation (testing, judging and refining) (QSA, 2003). On the surface these actions might read as phases that are linear in nature, and teachers might plan accordingly. In practice, students problem solve in cyclic, iterative, or even recursive ways between the actions which are similar to the integration of subtasks referred to by (Roth, Tobin \& Ritchie, 2001).

Other mathematical concepts could have been chosen as a focus, but ratio and proportional reasoning are central mathematical concepts (NCTM, 2004) and have been found to be particularly problematic to many adolescent female students. The construction of a variety of machines, some from provided plans and some of student design has offered the potential to link proportional reasoning to student production.

\section{Levels of Integration}

There were two levels of integration in the teaching intervention. First, across subject integration is termed "beyond mathematics integration." With respect to proportional reasoning, Schwartz, and Moore (1998) recommended that mathematics an d empirical knowledge (diagrams, pictures) were mutually supportive in developing understanding of this concept. Mathematics is a diverse subject domain, thus there exists potential for a second level of integration, which is integration between domains "within mathematics," a form of integration recommended by Lamon (1995). The importance of planning an emphasis on making connections within mathematics was central to Doig's (2001) description of highly effective teachers. By coincidence, the planned teaching intervention model was remarkably similar to that described by Ilany, Keret and Ben-Chaim (2004) in which authentic investigative activities for the teaching of proportion are described. 


\section{Summary of Literature and Relevance to the Study}

The literature cited above contains a mix of research methods including small qualitative case studies, large quantitative studies and meta-analysis. The main findings can be summarised as follows:

1. Mathematics is a gate keeper subject, central to participation in occupations vital to the national well being and there is an emerging shortage of female students studying applied mathematics subjects (subjects where mathematics is incorporated) in particular.

2. The proportion of girls taking intermediate and higher mathematics and proceeding to mathematically based subjects in science, engineering and technology remains relatively low. There are various explanations for this, not least those related to self-concept and perceptions of the way mathematics has traditionally been taught.

3. Proportional reasoning is a key middle school mathematics concept, which many students have struggled with. Researchers have recommended an approach to teaching proportional reasoning that connects a number of representations within authentic contexts and in problem solving situations.

4. Curriculum reforms have included a greater focus upon reasoning, studying mathematics in applied situations and integrated study of mathematics.

The focus of the study was analyse factors that may contribute to girls' disengagement with mathematics study and to seek pedagogical solutions for this. With the above background summary in mind, the aims of the study were as follows:

1. To investigate different pedagogic models for integrating mathematics and technology practice and draw inferences from the data regarding the effect of these models upon student learning and affect.

2. To evaluate the effectiveness of technology practice as a learning environment to teach mathematics, in particular proportional reasoning.

\section{Approach and Methodology}

\section{Background to Methodology}

The "design-based research" approach taken in the study had with two embedded case studies. Design-experiments were developed as a way to carry out formative research to test and refine educational designs based upon principles derived from prior research. More recently the term design-based research has been applied to this kind of work (Collins, Joseph, \& Bielaczyc, 2004). Design-based research blends empirical research with theory-driven design of learning environments, and it is useful in understanding how, when and why educational innovation works in practice (Design-Based Research Collective, 2003). A number of scholars have recommended this approach to 
understanding innovative learning experiences since it enables the intertwining of research and practice (e.g., Bell, 2004). Further, the methodology enables the researcher to adopt an interventionist, transformative stance that offers the opportunity to promote and sustain innovation (e.g., Bell, 2004). A critical aspect of design-based research is that development and research take place through cycles of design, enactment, analysis and re-enactment, analysis and further design. As in all design-based research studies, the specific research questions investigated in each iteration emerge from analysis of failures in previous iterations (Bell, 2004; Bereiter, 2002; Hoadley, 2004).

The research approach of intervening has much in common with participatory collaborative action research (Kemmis \& McTaggart, 2000) where the researcher and the teachers worked together to produce a meaningful change in the context of practice. The data collection and analysis methods were essentially mixed methods in that both quantitative and qualitative data collection procedures were used. In this study the quantitative component is used to describe any overall changes in student capacity to complete satisfactorily mathematical proportional reasoning tasks, and determine student attitude changes as a result of engagement in the classroom environment during the treatment. The qualitative component to the study serves to complement the quantitative findings by adding insights with respect of the causes of change.

\section{Design Phases and Data Collection}

The design-based research went through three phases. The first phase was the review of literature that prompted the planning and pedagogy of the first intervention in School 1. The review advocated the teaching of mathematics with an emphasis upon making connections between mathematics and authentic contexts, in particular, the design and construction of machines within a technology practice learning environment. While the principles of teaching mathematics through authentic activity have been well described, no research was uncovered with respect to teaching proportional reasoning through technology design practice. The second phase was the intervention in School 1 and the collection of data and its analysis. The third phase utilised the insights that emerged from the previous phase resulting in the implementation of a modified intervention in the second school (School 2). In both teaching interventions the researcher established a working relationship with the respective classroom teachers and taught 9 one and a half hour lessons in each over a 9 week period.

The collection of data included observations of students' interactions with objects, peers and teachers, students' planned and constructed artefacts, their explanations of how things worked, and written tests. Pre- and post- surveys were carried out assessing student attitudes in the dimensions of intention to study (e.g., I would like to study some SET in years 11 and 12), enjoyment (e.g., I really enjoy going to SET lessons) and intention to undertake a career in technology related fields (e.g., When I leave school, I would like to work with people who 
use SET and mathematics to solve problems), were assessed before and after the intervention using a modified TOSRA (Test of Science-Related Attitudes) scale (Fraser, 1981). Modifications to the survey included changing science to SET and defining SET and the role of mathematics in SET study.

In the post survey students were also asked to comment on the intervention, their learning of mathematics through technology practice, their feelings including enjoyment, how it may have impacted upon career and study intentions, how learning mathematics this way compared with the way they were traditionally taught and what recommendations they might have. Responses were audio taped and transcribed.

In both schools, interventions included pre- and post-tests for knowledge on proportional reasoning. The pencil and paper test had 18 questions. Some questions had simple and familiar contexts with structures such as:

To make drinks for sports day follow the recipe information given. (a) "Mix 1 litre of juice concentrate with 9 litres of water." What is the ratio of juice to water? (b) How many litres of juice concentrate is needed to make a sports drink that is 20 litres in total?

This question focuses on part/part and part/whole notions and can be solved with arithmetic thinking, including the construction of tables which can be done with repeated addition. Other questions focused on the between and within relationship in proportion (Lamon, 1995), for example,

My recipe for ANZAC biscuits states that I need two cups of rolled oats to make 35 biscuits. I want to make 140 biscuits, how many cups of rolled oats will I need?

The test included questions directly related to the subsequent construction learning contexts such as the inclusion of a diagram of a bicycle and the following question:

Explain the effect that turning gear A (attached to the pedals) with 24 teeth will have upon gear B which has 16 teeth on it (attached to the rear wheel).

Examine the diagram of the pulleys below. If the circumference of pulley $\mathrm{A}$ is 20 $\mathrm{cm}$ and the circumference of pulley $\mathrm{B}$ is $40 \mathrm{~cm}$ and the circumference of pulley $C$ is $10 \mathrm{~cm}$, and pulley $B$ is spun twice, describe how pulleys $A$ and $C$ will spin. Explain your answer.

Scoring was carried out on the basis of correctness and completeness of explanations. Over the duration of the study student explanations of their understanding of proportional reasoning was recorded in their written and verbal explanations, which were captured on audio or video.

The researcher has analysed multiple data sources in an attempt to describe the complex world of classroom teaching and provide a basis to question practice and inform further innovation and intervention. 


\section{Analytical Framework}

The qualitative analytical framework for describing how students worked uses the lens of activity theory (Leontyev, 1977; Engestrom \& Miettinen, 1999). The central aspect of activity theory is that the object connects individual actions to collective activity. Activity is always connected with the transformation of reality (Davydov, 1999). It is recognised that two basic processes operate continuously; internalisation and externalisation. Internalisation is related to the reproduction of culture and externalisation to the creation of new artefacts that makes possible this transformation (Engestrom \& Miettinen, 1999). Activity theory places people as actors in cultural contexts, shaping and being shaped by the physical environment (Leontyev, 1977). Frequently, models of activity theory show interacting triangles that include the nodes of Subjects (students, teachers and researcher), Instruments (Mediating artefacts, tools, scaffolding), Rules (classroom regulations and norms), Community (classroom community), Division of labour (roles of students and teachers) and Objects (learning outcomes) (see Roth, Tobin, Zimmermann, Natasia, \& Davis, 2002).

\section{Subjects and Situation of the Interventions}

Two classes in each of two schools were involved in the study. The first teaching intervention occurred in School 1 during the final semester of 2003, while the second intervention occurred in School 2 during the final semester of 2004. School 1 involved 56 Year 7 students in two classes in a co-educational State primary school located in a middle class suburb in Brisbane. Only the results of the 22 girls in these two classes are reported. The reason for this was that practicalities necessitated that the second intervention occur in a single sex school (School 2). The research outcomes relating to the boys in the classes of the School 1 were reported elsewhere (Norton, 2004).

School 1 was a trial school for New Basics Curriculum (Education Queensland, 2001) where attempts were being made to integrate the teaching of subject domains and a focus on authentic tasks. The two classroom teachers were also participants in the study. Jill (all names are pseudonyms) was a very experienced primary school teacher who also had extensive tertiary teaching experience and a passion for science. The second teacher, Cameron was also experienced in teaching this year level. In addition he had completed a science degree. School 1 became the second phase of the design-based research study.

In 2004 a similar unit of study was carried out in two Year 6 classes (with a total of 46 girls) in a private girls' school located in a middle class suburb in Brisbane (School 2). The researcher had hoped that the second iteration of the design-based research would be carried out with the same two teachers in the same school as in 2003, again with Year 7. However, School 1 did not wish to be involved in the second phase of the study, citing problems with timetabling. This necessitated a new school. The new school was private, single sex and the available classes were Year 6 . The two classroom teachers included Annie who was a very experienced primary school teacher and Louise, a first Year teacher having recently 
completed her degree in primary teaching. The intervention in School 2 represented the third phase of the project, the intervention in School 1 provided an opportunity to inform the intervention strategies for School 2. Technology practice including design was a feature of both the interventions. The differences in the schools and the differences in approaches meant that, in essence, the study was two case studies, the second building on the design learning of the first. Although it is unfortunate that the second intervention was not carried out in the same school as the first, I take some comfort from the findings of Lokan, Greenwood and Cresswell (2001) who noted that in their analysis of schools including both single sex, co-educational, private and State schools, about " $77 \%$ of the variance in mathematical literacy" could be explained by within school factors (p. 201). This finding suggests that different outcomes between the schools may well be attributed to different teaching approaches rather than differences in schools.

\section{Design Interventions and Results}

The results are presented in chronological order, the first intervention in School 1 occurred in the second semester of 2003, while School 2 intervention occurred in the second semester of 2004.

\section{Intervention for School 1- Case Study 1 (2003)}

Prior to teaching, the researcher and Jill matched both technology outcomes (Queensland Studies Authority, 2003) (QSA), and mathematics outcomes (QSA, 2004) with construction activities related to the "Simple and Powered Mechanisms" kits (Lego Educational Division, 2003). That is, planning focused on the "beyond mathematics integration." The kits contain a motor, various cogs and pulleys, various blocks, axles, connecting pieces as well as instruction booklets. In the first half of the intervention, students constructed Lego simple machines with the assistance of the relevant Lego plans (Lego Educational Division, 2003). Thereafter, they increasingly designed, constructed and evaluated according to their own designs and criteria.

As part of this technology practice process the students designed a tractor capable of beating other tractors in a "tug of war" and designed a working model of "something useful." The students also designed and produced self-propelled cars and measured their velocity as they moved over a known distance. In describing their artefacts the students were required to explain their products using mathematical concepts. Throughout the intervention the teachers and the researcher assisted the students to connect proportional thinking to the workings of the artefacts. This scaffolding of learning occurred in both small group and whole class discussion.

In implementing the unit, the teachers taught the associated mathematics in normal class time. The author did not engage in the detailed planning of the teaching of prerequisite mathematics or plan the "within mathematics" integration. Rather, the focus of planning was upon the integration of mathematics and technology practice or "beyond mathematics" integration. 
Quantitative and qualitative results for the first design intervention are described below. Student achievement on the pencil and paper mathematics tests is shown in Table 1 in the form of group mean scores and corresponding standard deviations. Qualitative data are also used to substantiate claims related to student cognitive gains.

Table 1

School 1. Pre and Post Test Results for Mathematics, total 24 marks

\begin{tabular}{llcr}
\hline & N & Mean & SD \\
\hline Pre-test & 21 & 9.64 & 4.02 \\
Post-test & 21 & $15.21^{* *}$ & 5.49 \\
\hline
\end{tabular}

**Significant at $\mathrm{p}<0.01$.

\section{Cognitive Outcomes}

It is encouraging to note that the mean results approximately doubled between pre- and post-testing. However, this result is not entirely surprising, given that the students had spent considerable time studying these concepts in a variety of settings. Not surprisingly, in the pre-test many students were able to give correct responses to questions that could be solved with simple additive projections. Students showed the greatest improvement on items that required a greater level of abstraction and multiplicative thinking.

Qualitative analysis of test items and of student explanations of constructed artefacts was based on the structural relationships associated with proportion including identifying "within quality relationships" and "between quality relationships" as described by Lamon (1995. p. 172). Figure 1 below illustrates an artefact designed to win a pulling competition constructed by two Year 7 girls.

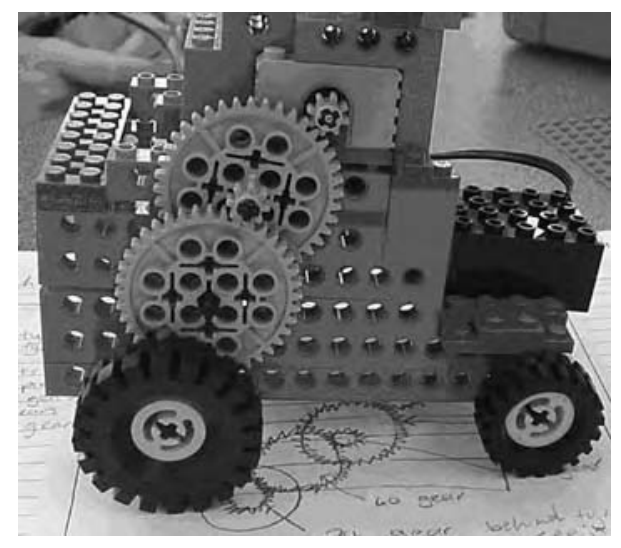

Figure 1. Tractor with low gearing, solid construction and counter weighted front. 
The results indicate that over half the students were developing understandings of proportion as evident in extracts of the qualitative data that follow. The explanation of gearing of the constructed tractor illustrates a quantitative explanation of gearing by two of the Year 7 students (Mary and Sarah) who constructed the tractor above.

The 8 teeth gear on the motor (driver) will turn the 40 teeth gear underneath it, (the driver) will turn 5 times, then 8 gear on the same bar as the 40 teeth gear will also turn 5 times, when the 8 gear turns 5 times, the gear with 40 teeth will turn once, making the 24 teeth gear that is behind the wheel turn around about 1 and $3 / 4$ times.

The students were aware that the drive had to turn 25 times to effect an outcome of "about 1 and $3 / 4$ times." The girls had initially tried to use a 40 tooth cog on the final drive but used a 24 tooth $\operatorname{cog}$ on this model. In order to overcome a construction challenge they used a 24 tooth cog rather than having the 40 tooth $\operatorname{cog}$ driving the rear wheels directly. Had the girls not used the 24 teeth cog the final ratio would have been 25:1. Clearly, the girls have presented very strong evidence that they had progressed in their ability to use proportional reasoning and ratio, and their description of the final ratio, 25 times is "about 1 and 3/4," is remarkably accurate. These girls also made considerable advances in their pre and post-tests on ratio and proportion related questions (Sarah, $43 \%$ to $77 \%$; Mary, $58 \%$ to $84 \%$ ). Consistent with the test data, not all students made such gains in their ability to apply and explain ratio concepts in the construction and explanation of the artefacts. Earlier studies have indicated that the percentage of middle school students who can apply proportional reasoning including comparing ratios is about $20 \%$ (e.g., Karplus, Pulos, \& Stage, 1983). Since the students experienced both traditional and applied learning (through the technology practice activities), we cannot determine the significance of the technology practice activities in enhancing proportional understanding from the test data. However, some of the student applications of these concepts as seen in their models and explanations suggest that their acquired understandings of proportional reasoning were beyond what has been found previously when students have been taught the concepts using traditional methods.

\section{Perception Outcomes}

Over the life of the first intervention there was a change in students' responses related to the dimensions of enjoyment of the intervention; intention to study mathematics/science/technology (SET) orientated subjects and career orientation with respect to SET on repeated measure statistics. The within subject comparison of pre-test and post-test was statistically significant for School $1(\mathrm{~F}=$ $7.78(2,54), \mathrm{p}<0.05$, partial eta squared $=0.742)$. The separate dimensions are reported below for School 1 (Table 2). 
Table 2

Pre and Post Intervention Results on the Attitude Dimensions for School 1

\begin{tabular}{llllc}
\hline & Mean & SD & N & Partial Eta Sq \\
\hline Enjoyment & 3.24 & 0.94 & 19 & 0.549 \\
Pre-trial & $2.47^{* *}$ & 1.06 & & \\
Post-trial & & & & \\
Study & 3.16 & 0.81 & 21 & 0.343 \\
Pre-trial & $2.66^{* *}$ & 0.86 & & \\
Post-trial & & & & \\
Career & 2.78 & 0.79 & 21 & 0.417 \\
Pre-trial & $2.16^{* *}$ & 0.76 & & \\
Post-trial & & & &
\end{tabular}

${ }^{*}$ Significant at $\mathrm{p}<0.01$.

Table 2 indicates that for School 1 there was a significant decline in attitude dimensions of enjoyment, intention to study similar subjects and intention to consider a career in such an area. It was clear that most girls did not have a strong positive tendency for learning through technology practice (reflected in mean scores around 3, undecided/neutral response) at the beginning of the intervention. It appeared that the intervention confirmed the unsure or noncommitted opinions that many girls had in relation to learning through this form of study, in spite of the fact some of these students made substantial knowledge gains. More importantly, in other cases the intervention served to help some students make up their mind to dislike learning through technology practice. This was particularly the case for five students who started with neutral or negative attitudes in the beginning of the study, and at the end of the intervention, reported attitudes that are more negative. In a few cases, there was increased motivation over the life of the intervention. Interestingly, several girls who had the most positive attitudes at the start of the study maintained their positive attitudes.

Interviews with students provided reasons for a decline in student affect related to the use of technology practice in the learning of mathematics. The concerns expressed by those students who demonstrated the greatest decline in attitude could be grouped into four broad areas as follows.

Concern 1: Enjoyment and scaffolding. The changed nature of the amount and form of teacher support offered was a negative aspect for five students as expressed in final interviews. For example:

Lyn: We like to learn maths and science like we normally do because it is quieter, and we are in ability groups and in my group, they teach you more how to do it. 
Cindy: I found it I very boring and I thought that it may have been more fun if we had more help and if we were more recognised. I think you guys should actually get the Lego and go to the front of the class and show us how to build it.

Becky: I have two problems. Firstly I found that the Lego robotics was poorly instructed and I had not enough help. I could not build a car from a book. The teacher should help us. And secondly, I only dislike technology because I have not been exposed to it. But after Lego I have found it frustrating and not clearly understood.

Each of these statements contains criticism for the lack of scaffolding offered by the researcher and the teachers concerned, particularly with respect to design and construction. The comments also reflect a lack of linkage between the activities and mathematical learning or beyond mathematics integration. The statements indicate that these girls wanted to be shown how to design and make. Classroom observations indicated that this lack of scaffolding was strongly linked to their disengagement with the subject, these girls frequently engaged in off task socialization.

In contrast, other students preferred the challenge of increased responsibility for their own learning (final interviews), for example:

Mary: I like building and finding out, I like to do it instead of being told.

Sarah: I would have liked to have more experiments and less time studying about velocity. The experiments were the most fun.

Chelsea: With this you are sort of investigating and finding out for yourself, (which is good) but with our teacher she is telling you to multiply this by this blah, blah, blah.

Concern 2: Links to mathematics. The second area of concern was a perceived poor linkage between the activity and specific mathematics learning:

Jill: I don't know how to build with Lego and I have not learnt anything useful. You never taught us and this annoys me. Doing this makes me dislike maths more than I already did. (beyond integration)

Anna: In a normal class you might spend a week on one thing, like perimeter, area, circumference and stuff like that. In this class we hardly learnt any maths. (within and beyond integration)

Andrea: But in this maths it is a bit from everywhere and it is confusing, (within integration).

These statements are evidence that some students found the processes of connecting technology practice activities with mathematics outcomes difficult because they were accustomed to a logical progression of subject development. In particular, Andrea and Anna expressed frustration at the lack of integration and connection of mathematical concepts, that is the "within mathematics 
integration." In contrast to traditional teaching of mathematics, in the construction activities concepts were drawn from different aspects of mathematics and this confused some students. On the other hand some students made clear links between mathematics and the activities as exemplified by discussion between Mary and Sarah in their explanations of their tractor gearing presented above.

Concern 3: Questions of relevance. Some students' negative attitudes were linked to their view that the knowledge embedded in the construction activities was irrelevant to their needs:

Liana: Yeah it works and it is good, you know it works and that is all you need to know. I want to own an equestrian school, and I do not need this stuff.

Sam: I want to be a fashion designer not a technology teacher. You do not need to explain how to build a car.

In contrast, other girls found the activities highly relevant:

Natasha: Well, for me it was good for my future job, because I want to be a builder so it has helped me to design cars and stuff. It has been good because we know what velocity is and how to test it.

Concern 4: Lack of recognition. Finally a number of students made comments such as "we could do a presentation" and "we need to be listened to," which suggests that they needed greater opportunity for social expression and recognition.

Five students who started with positive perceptions had this reinforced; about 10 retained an undecided or neutral perceptions and 5 students started with undecided perceptions and over the duration of the intervention this perception classified in the negative. The qualitative data indicated that some students needed to be provided with explicit scaffolding, more explicit linkage between technology practice activities and mathematical concepts (beyond mathematics integration), more careful sequencing of the teaching of mathematics concepts associated with the activity (within mathematics integration), a selection of tasks that might be considered to be more relevant and provide greater opportunity for students to achieve social recognition for their work. This knowledge was carried into the second iteration of the design-based research program.

\section{Intervention for School 2 - Case Study 2 (2004)}

Consistent with the design-based methodology, the results of the first intervention were used to refine the planning and pedagogy of the second intervention. The intervention in the second school involved an identical approach to data collection.

Similar to School 1, the concepts associated with velocity, revolutions, linear measurement, circumference (with radius, and pi) were identified. In order to 
take account of the findings from the first design intervention, the researcher and the teachers planned both "beyond mathematics integration" and "within mathematics integration." With respect to "within mathematics integration" the structural similarities and differences in fractions, decimals, percent, rate, scale and ratio were identified. The part/whole notions of fractions, decimals and percent were compared and contrasted with the part:part notions of ratio.

Within mathematics integration. During the second intervention fractions were taught with an emphasis on the sharing division and part/whole relationships. Payne and Rathmall's (1975) principles of constructing relationships between concrete materials, language and symbolism were emphasised throughout the study. Various representations were used including area, line, set and volume models. Multiple Attribute Blocks (MAB) or base ten blocks were used to link common fractions with fractions with a denominator of 10 or base 10 . For example a 10 rod could be viewed as the whole and students were asked to name the fraction shaded if 2 "one" blocks were shaded $(2 / 10$ or $1 / 5)$. Similarly, the students were asked to view the 100 square as the whole and the 1000 cube as the whole. MAB material was also used to make links to decimal notation, with students having to express parts of the whole as a decimal. While fraction operations were not taught, the multiplicative relationships associated with equivalent fractions were taught, using each of the models above (area, set, linear and volume), MAB materials and equivalent fraction strips. Students then represented simple fractions e.g., 2/100 as decimals (0.02) and percentages (2\%). That is, percent was seen as a special way of writing decimal fractions with the whole being 1 , or 100 hundredths. It was thought that linking to the base 10 number system would capitalise on students' prior experience with the decimal number system. Proportion was introduced by emphasising the part/part relationship of ratio as distinct from the part/whole relationship of fractions. The same models used to teach fractions (area, set, line, volume) were used to teach the part/part relationships involved in ratios including equivalent ratios. The structural similarities and differences between common fractions, decimals, percentage, and ratio were consolidated in the first one of three critical learning activities.

Beyond mathematics integration - critical learning activities. In order to take account of both "beyond mathematics integration" and "within mathematics integration," three critical learning activities were planned. In the first activity students were taken to the science laboratory and asked to make up solutions 1 part food dye with 9 parts water (volume model), 1 part food dye with 99 parts water, 1 part food dye with 999 parts water. As the students made up the dilutions they recorded the colour, ratio e.g., (1:9); fraction 1/10; decimal 0.1 and percent $10 \%$. The students repeated the dilution activity, but rather than making up $1 \mathrm{~mL}$ of dye with $99 \mathrm{~mL}$ of water, they took 1 drop of $10 \%$ solution and mixed it with 9 drops of water to make a 1:99 ratio or 1\% solution and compared the colours to the solutions they had made earlier. Students repeated the dilution process to make ratios to 1 part per million. Through such activities students were given multiple opportunities to distinguish between the part/whole 
relationship of fractions and the part:part relationships of ratio. Contextual links were also made.

The second major integration activity involved using fractions and proportional reasoning to determine if the Barbie doll was anatomically normal. It was anticipated that the Barbie study would help students to see the use of mathematics as relevant to their needs and interests. Research literature on adolescent girls' interests (e.g., Bloustien, 2003; Bowerler-Reyer, 1999; Cotterell, 1996; Pecora, 1999) indicated that at this phase of adolescent development considerations such as identity development, cultural icons and a focus on the feminine form would interest the students. Students designed their methods to test the hypothesis "Is Barbie a Monster?" They compared their own proportions (e.g. leg length to abdomen length (part:part); waist diameter to bust diameter (part:part), foot length to total height (part/whole-fraction) with that of the equivalent ratios and fractions on the Barbie dolls they investigated. Subsequently the students constructed 2 dimensional scale models of Barbie with cardboard, taking measurements of Barbie and multiplying by 5 to make the scale model the height of the average girl in the class. The students concluded that Barbie was indeed out of proportion and bore few similarities to any girl in the class.

The third critical learning integration activity required the students using their knowledge of proportional reasoning, to design, produce and evaluate cars with LEGO materials. The first car was designed to be fast, and the second to win a tug of war competition. Throughout the design and evaluation phases the students were encouraged to make their explanations for gearing used in the cars explicit and formal.

Integration of within and beyond mathematics learning. The planning process for the second intervention also differed from the process used for School 1. The planning for School 2 started with the mathematics outcomes, and activities were designed to progress these. In the first design intervention, it was more the case of "here are some construction activities, what mathematics is involved?" In addition, in the second intervention more attempts were made to take account of pre-requisite knowledge including the "within mathematics integration" and secondly, there was a more focused attempt to ensure that integration between mathematics and the activity and technology practice did occur. For example, the lessons preceding the dilution activity had concentrated on using alternative models to teach the concepts of fractions, decimals, percent and ratio. The dilution activity was an opportunity for students to apply this knowledge in a new context and also to explore the differences and similarities between these concepts. Similarly, the "Barbie activity" implemented concepts that had been explored using alternative models, however the application of ratio and proportional thinking with the added dimension of measurement was a new layer to the conceptual challenge. Finally, as part of the ideation, production and evaluation of cars, the application of gearing with the added conceptualisation of the relationship between circumference and diameter and the inverse relationship between size of a cog and number of times it needs to turn in order 
to turn another cog was present. To assist students to make links within and between mathematics and technology practice the researcher facilitated whole class and small group discussions at critical stages.

\section{Cognitive Outcomes}

Repeat measure statistics (see Table 3) indicated that the students in School 2 increased their knowledge of proportion and ratio problems in a similar manner to students in School 1, improving their scores by about $150 \%$.

Table 3

School 2 Pre and Post Test Results for Mathematics, total 24 marks

\begin{tabular}{llll}
\hline & $\mathrm{N}$ & Mean & SD \\
\hline Pre-test & 44 & 10.35 & 5.24 \\
Post-test & 44 & $16.17^{* *}$ & 4.62 \\
\hline
\end{tabular}

**Significant at $\mathrm{p}<0.01$.

Differences between the school circumstances, not least age of the students and the design-based research method suggest there is little merit in comparing the schools with respect to cognitive outcomes. What can be said is that in both schools there was significant progress in students' capacity to demonstrate proportional thinking as indicated in data from both pencil and paper tests and analysis of student explanations. As in School 1, students showed the greatest improvement on items that required a greater level of abstraction and multiplicative thinking.

\section{Perception Outcomes}

Given the student responses in School 1, it might be expected that a portion of the girls in School 2 would also exhibit a decline in attitude towards the study of mathematics in a design orientated classroom. However, the students in School 2 did not respond in a similar way to those of School 1 with respect to attitude change over the duration of the study. The within subject comparison of pre-test and post-test was statistically significant for School $2(\mathrm{~F}=14.054 ;(2,114), \mathrm{p}<0.00$; partial eta squared $=0.991$ ). The separate dimensions are reported in Table 4 for School 2.

These data are in contrast to those of School 1. In School 1 there was a statistically significant decline in scores on all dimensions of attitude, while in School 2 there was a statistically significantly improvement in attitude scores.

Enjoyment and scaffolding. As with the case of School 1 the higher partial statistics indicate that the enjoyment domain was the most important dimension contributing to the change in attitude. Qualitative analysis of the student responses on the surveys and to interviews adds meaning to the statistical results. 
Table 4

School 2 Pre and Post Intervention Results on Attitude Dimensions

\begin{tabular}{llllc}
\hline & Mean & SD & N & Partial Eta Sq \\
\hline $\begin{array}{l}\text { Enjoyment } \\
\text { Pre-trial }\end{array}$ & 2.84 & 0.48 & 39 & 0.405 \\
Post-trial & $3.31^{* *}$ & 0.66 & & \\
Study & & & & \\
Pre-trial & 3.11 & 0.37 & 39 & 0.230 \\
Post-trial & $3.42^{* *}$ & 0.58 & & \\
Career & & & & \\
Pre-trial & 2.81 & 0.64 & 39 & 0.345 \\
Post-trial & $3.23^{* *}$ & 0.61 & & \\
\hline
\end{tabular}

**Significant at $\mathrm{p}<0.01$.

Comments related to beyond and within mathematics integration scaffolding included:

Barbara: I like the way we worked on the white board and that way it was easier to understand it....Then if you wanted to make something go faster you could use it. (beyond mathematics integration)

Sally: I liked learning with the MAB and then mixing the dye. It made sense. (within mathematics integration)

Sarah: If you just gave it to me and we had not talked it over or anything, I would be feeling O.K., I don't really get this but, but since we talked about it, it as quite easy.(beyond mathematics integration)

Gabrielle: I liked it because we were learning through the object instead of just board work. (beyond mathematics integration)

Sophie: I don't think there is really anything that would make it better because it is fun and it has helped me understand pulleys. (beyond mathematics integration)

Links to mathematics. Some of the students made positive explicit reference to the lesson structure and the teaching of the prerequisite mathematics prior to engaging in construction activity or investigation. Their comments indicated that they liked to have the mathematical tools to understand the phenomena prior to embarking on technology practice and that the linkage between mathematics and the design and construction activity was transparent for them. Clearly, these students expressed a strong desire to understand relevant concepts as shown in the following evidence. 
Sam: I like the Barbie maths because it was enjoyable we were trying to figure out if the "perfect" Barbie was blown up to our size, would she look normal. It was a fun way to learn how to do ratios. (beyond mathematics integration)

Georgia: Yesterday we learnt all about ratio and we understood it more. If Barbie was a real human she would be approximately as thin a cat. The negative thing was that the people who made Barbie didn't make her in the right proportion. (within and beyond mathematics integration)

Barbara: It was very interesting comparing Barbie to a human. I never realised that she was so abnormal and how easy it was to tell!! It was great because now I understand ratio and find it easy to compare things. I have written these three ratios, they are all the same $(1: 9,2: 18,4: 36)$. (beyond and within mathematics integration)

Georgina: Her waist is just too small for her body and her legs...I think if Barbie was alive she would be very sad and lonely because she just would not fit in with any of the others.(beyond mathematics integration)

Lucinda: I liked the Lego, building the tractor, because I learnt how gears worked. (beyond mathematics integration)

Julie: If you wanted to make something go fast, you could use it (the understanding of ratio). (beyond mathematics integration)

The above comments suggest these students found the lessons to be authentic, relevant and linked to mathematical outcomes, which are in contrast with the ways most students perceived their usual lessons, for example:

Alyssa: Usually it is just written on the board and we just write in our book, plus, times, divide and just writing them down in our maths books.

Chantelle: I thought it was really good that we could investigate and not just like we usually do, the teacher would just say O.K., I'll write this on the board and you copy it down.

In addition, evidence indicated that the students found the activity fun as exemplified by Ruby's comment, "I reckon it was fun...We could go over it again and do some more work on it. For me it was hard work. The Lego was really fun."

In the second intervention, the researcher had planned lessons to ensure that students had opportunities to discuss the mathematics/technology concepts. The students neither expressed negative comments in interview situations about this aspect of the classroom environment, in particular the beyond and within mathematics integration, nor did they express concern with the social environment of the classroom. 


\section{Discussion}

\section{Examining Cognitive Changes}

In both schools the quantitative and qualitative data on student learning (tests, written and verbal explanations, artefacts) indicated that students had made comparable and significant advances in their understanding of concepts associated with proportion. Their test results improved by about $150 \%$ and means and standard deviations were comparable. Qualitative evaluation of explanations indicated similar improvements in each school with respect to students' being able to explain their thinking. Given the earlier research on student learning of proportional reasoning (e.g., Karplus et al., 1983) these results lend support for teaching this material in ways that enable students to reason, connect concepts, use the concepts with different materials and discuss authentic situations (e.g., Ben-Chaim, et al., 1998; Karplus, et al., 1983; Lo, \& Watanabe, 1997; National Science Foundation, 2005; Resnick, \& Singer, 1993). This is consistent with using the processes of externalization to assist in internalization processes of learning proportional thinking (Engstrom, \& Miettinen, 1999).

\section{Examining Changed Perceptions}

In this section I explain the different outcomes in terms of how the interactions between students and teachers (subjects), instruments (concrete artefacts and scaffolding in particular) produced different communities of practice with different perceptions. During the first intervention (School 1), data were collected from two mixed classes of Year 7 students in a State School setting, whereas during the second intervention, data were collected from two single sex Year 6 classes in a private school setting. The observed differences could be due to type of school, type of class, grade level, and other demographic differences not least social class (although both schools were located in middle class suburbs). For example, the presences of boys in the class may have impacted on the girl's perceptions. However, the author takes some comfort from Lokan et al., (2001) who indicated that about $80 \%$ of performance and affective variance can be explained by within school factors, suggesting that the difference in attitude can be attributed to the different treatments. In addition, initially in both schools the students reported approximately neutral perceptions of enjoyment, intention to study and career orientation (Table 2 and Table 4 ). By the end of the intervention about a quarter of the girls in School 1 had rejected the intervention methods associated with technology practice. This attitude decline was strongest in the case of enjoyment. Students in the first school who expressed disenchantment provided reasons that fell into four broad categories; the form of scaffolding; lack of linkage to mathematics, relevance of tasks, and a lack of social forum opportunities. We might expect then that a portion of students in the second study would do likewise.

In the second intervention, perceptions including attitude toward study of mathematics in a technology practice learning environment improved from pre 
test to post test, again enjoyment accounting for most of the changed attitude. The finding that almost all students in School 2 improved in their attitude towards this form of mathematics learning suggests that the pedagogical treatment may well have been a significant factor in explaining the differences between the schools. The qualitative data supports this tentative assertion.

Enjoyment and scaffolding. It has been previously reported that many students are comfortable with teachers who tell them what to do (e.g., Kagan, 1992). Maccoby and Jacklin, (1974) presented evidence that girls were more likely to favour this form of teaching. In this regard, girls in this study who resented the reduction of scaffolding and demanded to be shown how to build have behaved consistently with previous findings (e.g., Kagan, 1992; Maccoby, \& Jacklin, 1974). It was encouraging that most girls did not fall into this category and some expressed a preference for more autonomous learning. This find is consistent with girls taking a more holistic view of problem solving. It also supports recent research on engagement of girls with Lego Robotics (e.g., Edminston, 2003).

Within mathematics linkage. The interview comments of students in School 1 indicated that some of the girls did not see the relationships that existed between various mathematics concepts and they expressed frustration about this. This was typified by comments such as "This maths is coming from everywhere." The opposite view was the case in School 2, where providing the students with opportunities to understand links between mathematical concepts (e.g., fractions, decimals, percent and ratio) was well received. In the second intervention, explicit scaffolding was provided. Students were taught the necessary prerequisite knowledge to understand the mathematics underpinning design constructions and they mathematics was linked to the artifacts when students were working on them. The students commented that the activities were fun and helped them to understand proportional thinking. Their comments indicated that the "within mathematics integration" helped them see the learning in a more connected and holistic way, and consistent with the findings of Head (1996), these females expressed a preference for embedded thinking.

Beyond mathematics links. A second reason for more negative perceptions about mathematics learning in the context of technology practice in the first intervention was the perceived lack of linkage to specific mathematics outcomes or "beyond mathematics integration." This was typified by comments such as "I have not learnt anything useful." Such a comment highlights the difficulty of attempting to teach a topic that is generally regarded as a highly structured body of knowledge (Ernest, 1991) in a contextual setting. That is, the recommendation to contextualise mathematics (and hard sciences) as a means of increasing student motivation and learning (e.g., Education Queensland, 2001; Malcolm, 2002; National Science Foundation, 2005; Victorian Curriculum and Assessment Authority, 2005) was not appreciated by all students in this study. Interestingly, some girls who improved their test results recorded more negative perceptions about learning through technology practice, including reduced intention to undertake further technology study and reduced liking of mathematics. This finding stands at odds with the expectancy models proposed by Eccles et al. 
(1983) and Ethington (1992) but is consistent with the findings of Lokan et al (2001).

In the second intervention better perception outcomes were achieved through the selection of appropriate tasks (dilution activity; Barbie activity; car design and construction) that focused on proportional thinking. This was associated with explicit scaffolding to assist "within mathematics integration" by linking the multiplicative structures associated with proportion to those of equivalent fractions and the base 10 number system. Evidence indicates that when students were given the scaffolding to assist them to understand both the within mathematics integration and the linkages between mathematics and construction activity, it appeared they were able to see the value of mathematics in explaining modeling phenomena. This appeared to contribute to overall increased positive perceptions towards the study of mathematics in general and mathematics through technology practice in particular. This finding is consistent with postmodernist feminist pedagogies that emphasise the importance of personal relevance of students' experiences (e.g., Brady \& Denith, 2001; Head, 1996; Walkerdine, 1988).

It became apparent that the girls in the study had specific views in terms of what was authentic and engaging to them. A number of girls in the first school did not consider the building of cars, cranes and tractors to be authentic and relevant tasks and the knowledge of them was not considered useful. However, girls in the second school did not express a similar view to cars cranes and tractors, possibly because they had been given the tools to understand the underpinning mathematics. Results that indicated the Barbie activity had motivational potential for girls in the process of defining their own identity and with an interest in body image are consistent with findings by other researchers (e.g., Bloustien, 2003; Bower-Reyler, 1999).

The findings demonstrate that there is a need for the embedding of mathematics within gender specific tasks and to take account of preferred learning styles and scaffolding needs. This means teachers need to search for the types of tasks that the students are likely to find authentic and engaging and are rich in mathematics. This does not mean that the teachers allow individual students to conduct their own diverging projects. If such a situation were to develop, it is likely that the teacher would be placed in the position of trying to supply pre-requisite knowledge needs, point of need scaffolding and to facilitate whole group discussions on a range of topics. It has been noted previously that this is not a trivial task (McRobbie, Nason, Jamieson-Proctor, Norton, \& Cooper, 2000; Sfard, Nesher, Streefland, Cobb, \& Mason, 1998), since it makes the task of making explicit within mathematics and beyond mathematics integration difficult.

\section{Conclusions}

The goal of this study was to reproduce cultural knowledge (understanding of proportional reasoning). It was found that through the process of design and construction of new artefacts (activity) proportional understanding facilitated, an approach consistent with that recommended by Engstrom and Miettinen, (1999). 
In both schools students enhanced their knowledge about proportional reasoning, the cognitive object of the study. However, it was apparent that some groups of students from each school developed different affective objects (perceptions), in particular, enjoyment and inclination to carry out study in similar domains under similar conditions. There appeared to be credible evidence from the collected data that the different teaching approaches have accounted for much of this difference. The students in the first intervention expressed the desire that, on occasions the teacher should provide explicit scaffolding and whole class engagement to make the mathematics linkages to the activity explicit. By refining the planning and pedagogy based on findings in the first intervention, clearer links were made with regard to activity and outcomes in the second intervention. The different perception results in the schools indicated that more overt attempts to demonstrate the "within mathematics integration" and "beyond mathematics integration" links for students in School 2 may account for a positive student affect. The differences in student evaluations of the learning processes indicated that most of the students in School 2 appreciated specific scaffolding to understand and connect design and construction activity to mathematical ideas.

The changes in perceptions (negative in School 1 and positive in School 2) and specific student comments suggest that task selection needs to be authentic, remembering that perceptions of authenticity were linked to capacity to understand. In terms of the analytical lens of activity theory, differences in perceptions development were related to the different rules and divisions of labour (scaffolding and classroom activity), integration between instruments (number, measurement and construction of artefacts) such that learning objects including positive perceptions could be achieved.

Finally, it was apparent that the girls in the study preferred tasks to have a useful purpose and to be able to share their understandings with the class. Clearly this presents a further opportunity to increase integration both within and beyond mathematics thinking. The findings support those of activity theorists who contend that understanding can be built up through activity with the concrete conditions of life including the social nature of individuals (Tolman, 1999), as well as postmodernist feminist pedagogies (Brady, \& Denith, 2001). The study helps to identify how externalisation and internalisation can be linked through instruments (especially scaffolding), rules (especially requiring students to make links and concepts explicit), and through the design and construction of authentic artefacts. The findings of this study suggest that further longitudinal design-based research including controls in a variety of different settings, is warranted. 


\section{References}

Australian Academy of Technological Sciences and Engineering (2002). The teaching of science and technology in Australian primary schools: A cause for concern. Melbourne: Australian Academy of Technological Sciences and Engineering.

Barrington, F. (2006). Participation in year 12 mathematics across Australia 1995-2004. Melbourne: International Centre of Excellence in Mathematics and Australian Mathematical Sciences Institute.

Batterham, R. (2000). The chance to change: Final report of the chief scientist. Canberra: Commonwealth of Australia.

Bell, P. (2004). On the theoretical breadth of design-based research in education. Educational Psychologist, 39(4), 243-253.

Ben-Chaim, D., Fey, J. T., Fitzgerald, W. M., Benedetto, C., \& Miller, J. (1998). Proportional reasoning among 7 th grade students with different curricular experiences. Educational Studies in Mathematics, 36, 247-273.

Bereiter, C. (2002). Design research for sustained innovation. Cognitive Studies, Bulletin of the Japanese Cognitive Science Society, 9(3), 321-327.

Bloustien, G. (2003). Girl making: A cross-cultural ethnography on the process of growing up female. New York: Berghahn Books.

Boaler, J. (1997). Experiencing school mathematics: Teaching styles, sex and setting. Buckingham, United Kingdom: Open University Press.

Bowler-Reyer, A. (1999). Becoming a woman in the 1970's: Female adolescent sexual identity and popular literature. In S. R. Mazzarella, \& N. O. Pecora (Eds.), Growing up girls: Popular culture and the construction of identity (pp. 21-48). New York: Peter Lang.

Brady, J., \& Dentith, A. (2001). Critical voyages: Postmodern feminist pedagogies as liberatory practice. Teaching Education, 12(2), 167-176.

Collins, A., Joseph, D., \& Bielaczyc, K. (2004). Design research: Theoretical and methodological issues. Journal of the Learning Science, 13(1), 15-42.

Cooper, T., Nuyen, A., \& Baturo, A. (2003). Rich task project: Integrated mathematics outcomes with rich tasks within a productive pedagogies framework. Queensland University of Technology. Available from: http://education.qld.gov.au/corporate/newbasics/ pdfs/richtaskrep3-final-8.4.03.pdf+Nuyen+Cooper+Baturo

Cox, P. J., Leder, G. C., \& Forgasz, H. J. (2004). Victorian Certificate of Education: Mathematics science and gender. Australian Journal of Education, 48(1), 27-47.

Cotterell, J. (1996). Social networks and social influences in adolescence. London: Rutledge.

Custer, R. (2003). Technology education in the United States - A status report. In G. Martin, \& H. Middleton (Eds.), Initiatives in technology education: Comparative perspectives (pp. 16-29). Brisbane: Technical Foundation of America \& Centre for Technological Education Research, Griffith University.

Davydov, V. (1999). The content and unsolved problems of activity theory. In Y. Engestrom, R. Miettinen, \& R. Punamaki (Eds.), Perspectives on activity theory (pp. 39-53). Cambridge, United Kingdom: University Press.

De Bono, E. (2004). Thinking course: Powerful tools to transform your thinking. London: BBC Books.

De Corte, E. (2004). Mainstreams and perspectives in research on learning (mathematics) from instruction. Applied Psychology, 53(2), 279 - 310. Available online from: http: / / www.blackwell-synergy.com/links/doi/10.1111/j.1464-0597.2004.00172.x/full

Design-Based Research Collective. (2003). Design-based research: An emerging paradigm for educational inquiry. Educational Researcher, 32(1), 5-8. 
Doig, B. (2001). Summing up: Australian numeracy performances, practices, program and possibilities. Melbourne: Australian Council for Educational Research Ltd. Available from: http://www.acer.edu.au/research/reports/documents/Doig_Summing_Up.pdf

Eccles, J. S., \& Wigfield, A. (1995). In the mind of the actor: The structure of adolescents' achievement task value and expectancy-related beliefs. Personality and Social Psychology Bulletin, 21, 215-225.

Eccles, J., Adler, T., Futterman, R., Goff, S., Kaczala, C., Meece, J., \& Midgley, C. (1983). Expectancies, values, and academic behaviors. In J. Spence (Ed.), Achievement and achievement motives (pp. 75-146). San Francisco: W.H. Freeman.

Edminston, G. (2003). Design inclusive curriculum: Engaging girls with science, engineering and technology. Unpublished master's thesis, University of Queensland, Brisbane.

Education Queensland. (2001). New Basics project: Technical paper. Retrieved July 1, 2003, from: http:/ /education.qld.gov.au/corporate/newbasics/docs/nbftech.doc.

Engstrom, Y., \& Miettinen, R. (1999). Introduction. In Y. Engestrom, R. Miettinen, \& R. Punamaki (Eds.), Perspectives on activity theory (pp. 1-18). Cambridge, United Kingdom: Cambridge University Press.

Ernest, P. (1991). The philosophy of mathematics education, London: Falmer.

Ethington, C. (1992). Gender differences in a psychological model of mathematics achievement. Journal for Research in Mathematics Education, 23(2), 166-181.

Fennema, E. (1996). Scholarship, gender and mathematics. In P. F. Murphy \& C. V. Gipps (Eds.), Equity in the classroom: Towards effective pedagogy for girls and boys (pp. 73-80). London: Falmer.

Fraser, B. (1981), TOSRA: Test of science-related attitudes. Melbourne: Australian Council for Educational Research.

Head, J. (1996). Gender identity and cognitive style. In P. F. Murphy \& C. V. Gipps, (Eds.), Equity in the classroom: Towards effective pedagogy for girls and boys. (pp. 59-70). London: Falmer.

Hoadley, C.M., (2004). Methodological alignment in design-based research. Educational Psychologist, 39(4), 202-212.

Hollingsworth, H., Lokan, J., \& McRae, B. (2003). Teaching mathematics in Australia: Results from the TIMSS 1999 Video study. Melbourne, Australian Council for Educational Research. Available from: http://www.timss.acer.edu.au/documents/TIMSSV_ Report.pdf

Ilany, B-S., Keret, Y., \& Ben-Chaim, D. (2004). Implementation of a model using authentic investigative activities for teaching ratio \& proportion in pre-service teacher education. In M. J. Hoines \& A. B. Fugestad (Eds.), Proceedings of the 28th conference of the International Group for the Psychology of Mathematics Education (Vol. 3, pp. 81-88). Bergen, Norway: PME.

Jones, G., Langrall, C., Thorton, C., \& Nesbit, S. (2002). Elementary students' access to powerful mathematical ideas. In L. English (Ed.), Handbook of international research in mathematics education (pp. 113-141). Mahwah, NJ: Erlbaum.

Kagan, D. M. (1992). Implications of research on teacher belief. Educational Psychologist, 27(1), 65-90.

Karplus, R., Pulos, S., \& Stage, E. (1983). Proportional reasoning of early adolescents. In R. Lesh \& M. Landan (Eds.), Acquisition of mathematical concepts and processes. (pp. 44-90). Orlando, FL: Academic Press.

Kemmis, S., \& McTaggart, R. (2000). Participatory action research. In N. K. Denzin \& Y. S. Lincoln (Eds.), Handbook of qualitative research (pp. 567-606). Thousand Oaks, CA: Sage.

Lamon, S. (1995). Ratio and proportion: Elementary didactical phenomenology. In J. T. Sowder \& B. P. Schappelle (Eds.), Providing a foundation for teaching mathematics in the middle grades (pp. 167 -197). Albany, NY: State University of NY Press. 
Lokan, J., Forbes, P., \& Greenwood, L. (1996). Maths and science on the line: Australian junior secondary students' performance in the Third International Mathematics and Science Study. [TIMSS Australia Monograph No. 1]. Melbourne: Australian Council for Educational Research.

Lokan, J., Ford, P. \& Greenwood, L. (1997). Maths \& Science on the Line: Australian Middle Primary Students' Performance in the Third International Mathematics and Science Study. [TIMSS Australia Monograph No. 2.] Melbourne: ACER.

Lokan, J., Greenwood, L., \& Cresswell, J. (2001). 15-up and counting, reading, writing, reasoning: How literate are Australia's students? The PISA 2000 survey of students' reading, mathematical and scientific literacy skills. Melbourne: Australian Council for Educational Research.

Lego Educational Division. (2003). Simple and powered mechanisms: Teacher's guide. United Kingdom: Author.

Leontyev, A. N. (1977). Activity and consciousness: Philosophy in the USSR, problems of dialectical materialism. Progress Publishers. Retrieved February 17, 2004, from http://www.marxists.org/archive/leontev/works/1977/leon1977.htm.

Lo, J-J. \& Watanabe, T. (1997). Developing ratio and proportion schemes: A story of a fifth grader. Journal for Research in Mathematics Education 28(2), 216-236.

Ma, X., \& Kishor, N. (1997). Assessing the relationship between attitude toward mathematics and achievement in mathematics: A meta-analysis. Journal for Research in Mathematics Education, 28(1), 26-47.

Ma, X., \& Willms, J. D. (1999). Dropping out of advanced mathematics: How much do students do and schools contribute to the problem? Educational Evaluation and Policy Analysis, 21(4), 365-393.

Maccoby, E. E., \& Jacklin, C. N. (1974). The psychology of sex differences. Stanford Palo Alto, CA: Stanford University Press.

Macklin, J. (2005) Media Release 26 April 2005.http://jennymacklin.net.au/infocentre. asp?data $=480 \mathrm{E} 0 \mathrm{~F} 0504094 \mathrm{~F} 5851515 \mathrm{E} 587 \mathrm{E} 45555 \mathrm{~F} 48454 \mathrm{~B} 4 \mathrm{E}$

Malcolm, C. (2002, October). Science and technology education in the smart state: But what is smart? Proceedings of the science works for the smart state. Brisbane: Education Queensland.

McRobbie, C. J., Nason, R., Jamieson-Proctor R., Norton, S. \& Cooper, T. J. (2000). The influence of computer-rich learning environments on mathematics achievement. In M. Thomas (Ed.), Proceedings of Technology in Mathematics Education (TIME Auckland) (pp. 187-194). Auckland, NZ: University of Auckland \& Auckland University of Technology.

Murdoch, K., \& Hornsby, D. (2003). Planning curriculum connections: Whole-school planning for integrated curriculum. Melbourne: Eleanor Curtain Publishing.

Nabors, W. (2002). On the path to proportional reasoning. In A. D. Cockburn \& E. Nardi (Eds.). Proceedings of the 26th annual conference of the International Group for the Psychology of Mathematics Education (Vol. 3, pp. 385-401). Norwich, United Kingdom: PME.

Nason, R., \& Woodruff. E. (2003). Fostering authentic, sustained and progressive mathematical knowledge-building activity in computer collaborative (CSCL) communities. Journal of Computers in Mathematics and Science Teaching, 22(4) 345-363.

National Council of the Teachers of Mathematics. (1989). Curriculum and evaluation standards for school mathematics. Reston, VA: The Council.

National Council of Teachers of Mathematics. (2004). Principles and standards for school mathematics: Introduction. Retrieved March 22, 2004, from: http://Standards.nctm. org/documents/chapter1/index/html. 
National Science Foundation. (2005). Connected Mathematics Project. Available from http:/ / www.math.msu.edu/cmp/index.html

Norton. S. J. (2004). Using Lego construction to develop ratio understanding. In I. Putt, R. Faragher \& M. McLean (Eds.), Mathematics education for the third millennium: Towards 2010 (Proceedings of the 27th annual conference of the Mathematics Education Research Group of Australasia, Townsville, Vol. 2, pp. 414-421). Sydney: MERGA

Norton, S. J., McRobbie, C. J., \& Ginns, I. S. (2004). Student approaches to design in a robotics challenge. In H. Middleton, M. Pavlova \& D. Roebuck (Eds.), International Conference on Technology in Educational Research (pp. 26-36). Gold Coast, 9 - 11 December.

Payne, J., \& Rathmell, E. (1975). Number and numeration. In J. N. Payne (Ed.), Mathematics learning in early childhood (pp. 125-160). Reston, VA: NCTM.

Pearn, C., \& Stephens, M. (2004). Why do you have to probe to discover what Year 8 students really think about fractions. In I. Putt, R. Faragher, \& M. McLean (Eds.), Mathematics education for the third millennium: Towards 2010 (Proceedings of the 27th annual conference of the Mathematics Education Research Group of Australasia, Townsville, Vol. 2, pp. 430-437). Sydney: MERGA.

Pecora, N. (1999). Identity by design: The corporate construction of teen romance novels. In S. R. Mazzarella \& N. O. Pecora, (Eds.), Growing up girls: Popular culture and the construction of identity (pp. 49-86). New York: Peter Lang.

Resnick, L., \& Singer, J. (1993). Protoquantitative origins of ratio reasoning. In T. Carpenter, E. Fennema \& T. Romberg (Eds.), Rational numbers: An integration of research (pp. 107-129). Hillsdale, NJ: Erlbaum.

Roth, W., Tobin, K. Zimmerman, A., Natasia, B., \& Davis, C. (2002). Lessons on and from the dihybrid cross: An activity-theoretical study of learning in co-teaching. Journal of Research in Science Teaching, 39(3), 253-282.

Roth, W-M., Tobin, K., \& Ritchie, S. (2001). Re/Constructing elementary science. New York: Peter Lang.

Queensland Studies Authority. (QSA). (2004). Mathematics Years 1 to 10 syllabus. Retrieved September, 18, 2003.http://www.qsa.qld.edu.au/yrs1_10/kla/mathematics/index. html.

Queensland Studies Authority. (QSA). (2003). Technology: Years 1-10 syllabus. Brisbane: Queensland Studies Authority.

Schwartz, D. L., \& Moore, J. L. (1998). On the role of mathematics in explaining the material world: Mental models for proportional reasoning. Cognitive Science: A Multidisciplinary Journal, 22(4), 471-516.

Sfard, A., Nesher, P., Streefland, L., Cobb, P., \& Mason, J. (1998). Learning mathematics through conversation: Is it is as good as they say? For the Learning of Mathematics, 18(1), 41-51.

Thompson, A. G. (1992). Teachers' beliefs and conceptions: A synthesis of the research. In D. A. Grouws (Ed.), Handbook of research on mathematics teaching and learning (pp. 127-146). New York: National Council of Teachers of Mathematics.

Tolman, C. (1999). Society versus context in individual development: Does theory make a difference? In Y. Engestrom., R. Miettinen \& R. Punamaki (Eds.), Perspectives on activity theory (pp. 70-86). Cambridge, UK: Cambridge University Press.

Townend, M, S. (2001). Integrating case studies in engineering mathematics: A response to SARTOR 3. Teaching in Higher Education, 6(2), 203-215.

Trauth, E. M., Nielsen, S., \& von Hellens, L. (2003). Explaining the IT gender gap: Australian stories for the new millennium. Journal of Research and Practice in Information and Technology, 35(1), 7-20. 
Victorian Curriculum and Assessment Authority. (2005). Victorian Essential Learning Curriculum. Available from: http:/ /vels.vcaa.vic.edu.au/

Walkerdine, V. (1998). Counting girls out: Girls and mathematics. Bristol, PA: Falmer.

\section{Author}

Stephen Norton, Logan Campus, Griffith University, University Drive, Meadowbrook, QLD, 4131. Email: <s.norton@griffith.edu.au> 